\title{
Submental intubation: An alternative to tracheostomy when nasoendotracheal intubation is unsuccessful - A case report
}

\author{
Johnny Franco MD, Jeffrey Coppage MS, Michael Fallucco MD, John Scott Ferguson MD
}

\begin{abstract}
J Franco, J Coppage, M Fallucco, JS Ferguson. Submental intubation: An alternative to tracheostomy when nasoendotracheal intubation is unsuccessful - A case report. Can J Plast Surg 2009;17(4):e37e38.

Submental intubation (SI) has been proposed as an alternative to nasoendotracheal intubation when oral endotracheal intubation is contraindicated. In patients who require intubation for maxillofacial reconstruction, this is an alternative to a traditional tracheostomy. The present case report presents an 18-year-old woman who suffered a comminuted mandibular fracture. Two days after her accident, she was taken to the operating room for open reduction with internal fixation of her mandible; however, the anesthesia staff was unable to nasally intubate the patient. A SI was performed. The procedure was completed without complications and the surgery accomplished with the SI. The patient was able to avoid a tracheostomy for an isolated operation. SI avoids the dangers of nasoendotracheal intubation in patients with midfacial fractures and avoids complications related to tracheostomy. Thus, SI may serve as an alternative to tracheostomy in patients without other medical conditions and indications for long-term intubation.
\end{abstract}

Key Words: Facial fractures; Maxillomandibular fixation; Maxillofacial reconstruction; Submental intubation

\section{Intubation sous-mentale : Solution de rechange à la trachéotomie quand l'intubation nasoendotrachéale échoue - Rapport de cas}

L'intubation sous-mentale (ISM) a été proposée comme solution de rechange à l'intubation nasoendotrachéale lorsque l'intubation endotrachéale orale est contre-indiquée. Chez les patients qui ont besoin d'une intubation pour une reconstruction maxillofaciale, il s'agit d'une solution de rechange à la trachéotomie classique. Le présent rapport décrit le cas d'une jeune femme de 18 ans qui a subi une fracture mandibulaire comminutive. Deux jours après son accident, elle a été admise au bloc opératoire pour réduction ouverte avec fixation interne du mandibule. Toutefois, le personnel de l'anesthésie a été incapable d'intuber la patiente par voie nasale. Une intubation sous-mentale a donc été effectuée. L'intervention s'est déroulée sans complications et la chirurgie a pu être réalisée avec l'ISM. La patiente a ainsi évité la trachéotomie pour une opération ponctuelle. L'ISM permet d'éviter les dangers de l'intubation nasoendotrachéale chez les patients qui souffrent de fractures faciales multiples, de même que les complications liées à la trachéotomie. Donc, l'ISM peut constituer une solution de rechange à la trachéotomie chez les patients qui ne présentent pas d'autres problèmes de santé et qui n'ont pas besoin d'une intubation prolongée.

\begin{abstract}
A irway management in patients with facial trauma requiring operative intervention can present a unique challenge to both the anesthesiologist and the surgeon. Submental intubation (SI) has been described as an alternative to nasoendotracheal intubation when oral endotrachel intubation is contraindicated. Contraindications to nasotracheal intubation include basal skull fractures, which have lead to intracranial malposition of nasopharyngeal airway $(1,2)$.

The present case report highlights the successful implementation of an alternative approach first described in 1986 by Hernandez Altemir (3). SI offers an alternative to tracheostomy in patients requiring an isolated operation for facial reconstruction. In addition, submental intubation can be performed in less than 5 min (4) and few complications, such as superficial wound infection (4) and mucocele formation (5), have been reported. No cases of injury to the structures of the floor of the mouth, associated glands or hemorrhage have been reported (4). The present case report describes the use of the SI in the setting of facial trauma where nasotracheal intubation was unable to be obtained.
\end{abstract}

\section{CASE PRESENTATION}

An 18-year-old woman presented to the emergency department after suffering a fall from the second story window of her house. On presentation, she was able to protect her airway and did not require intubation. She was admitted for observation and pain management due to her comminuted left mandibular fracture and bilateral displaced condylar fractures.

On hospital day 3 she was taken to the operating room for repair of her facial fractures. Her respiratory status had been stable throughout her hospital stay and, thus, she was never intubated before her operative intervention. The patient was to be nasally intubated because she required access to her oral cavity during the procedure and maxillary mandibular fixation postoperatively. The anesthesia staff attempted multiple times to perform nasoendotracheal intubation and were unsuccessful. Fibre optic assistance was also attempted; however, the anesthesia staff did not feel that the patient could be intubated safely. The trauma surgeon was called into the room to perform a tracheotomy to provide an airway for the patient; however, before tracheotomy it was decided to attempt to perform a SI.

The patient was intubated initially via standard oral endotracheal intubation technique and this was converted to a SI by the surgical team. A spiral armored endotracheal tube was used. Then, a $1.5 \mathrm{~cm}$ incision was made immediately to the right of the midline in the floor of the mouth and blunt dissection was done through the submental region

Saint Louis University, Department of Surgery, Division of Plastic Surgery, School of Medicine, Saint Louis, Missouri, USA

Correspondence: Dr Johnny Franco, 1010 Charles Street, Apartment 308, Saint Louis, Missouri 68715, USA. Telephone 575-496-3774,

e-mail jufranco16@gmail.com 


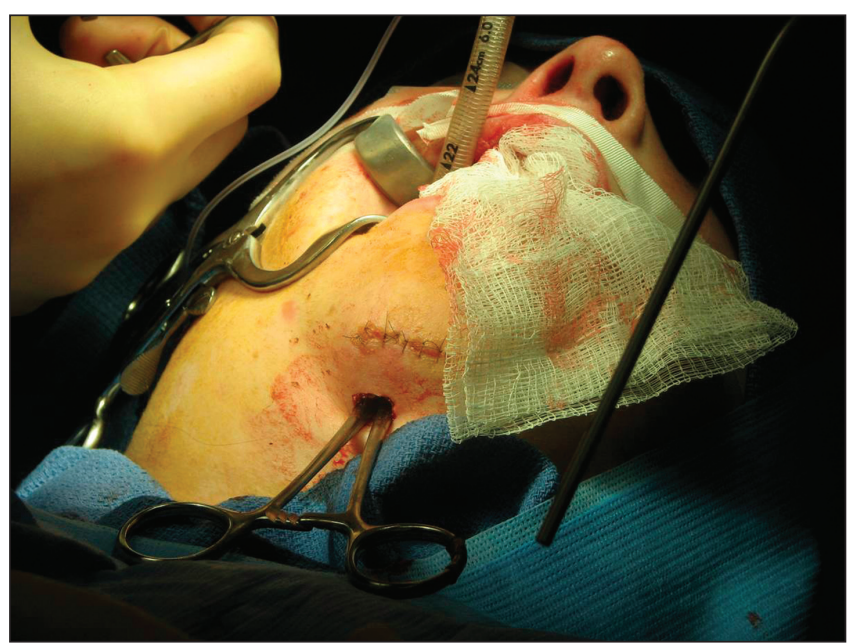

Figure 1) Submental dissection

of the face (Figure 1). Once dissection through the floor of the mouth was completed, the endotracheal tube was pulled through the dissected tract and out of the submental region of the face (Figure 2).

\section{DISCUSSION}

SI has recently been described as an alternative to tracheostomy when oral endotracheal intubation is contraindicated. SI is indicated when intraoperative maxillomandibular fixation is necessary and a nasal intubation is not possible or contraindicated (6). Traditionally, patients have had their airway secured via a tracheotomy when nasal intubation was contraindicated or unable to be obtained. The present case report highlights the benefits of SI in a patient with no longterm need for ventilatory support, but the need for intubation for operative procedures.

In patients without a need for long-term intubation, SI provides an attractive alternative to a tracheostomy. It allows the patient to avoid the stigmata of a tracheostomy scar and is replaced with an inconspicuous scar hidden under the mandible. Reported complications include submental wound infection, abscess formation in the floor of the mouth, salivary fistula, mucocele formation and hypertophic scarring (6). However, a recent series by Biglioli et al (4) reviewed 24 consecutive patients that underwent SI over a six-year period for transfacial cranial base surgery and reported only one complication, a superficial wound infection (4). Caron et al (8), in their study of 25 patients with panfacial and midfacial

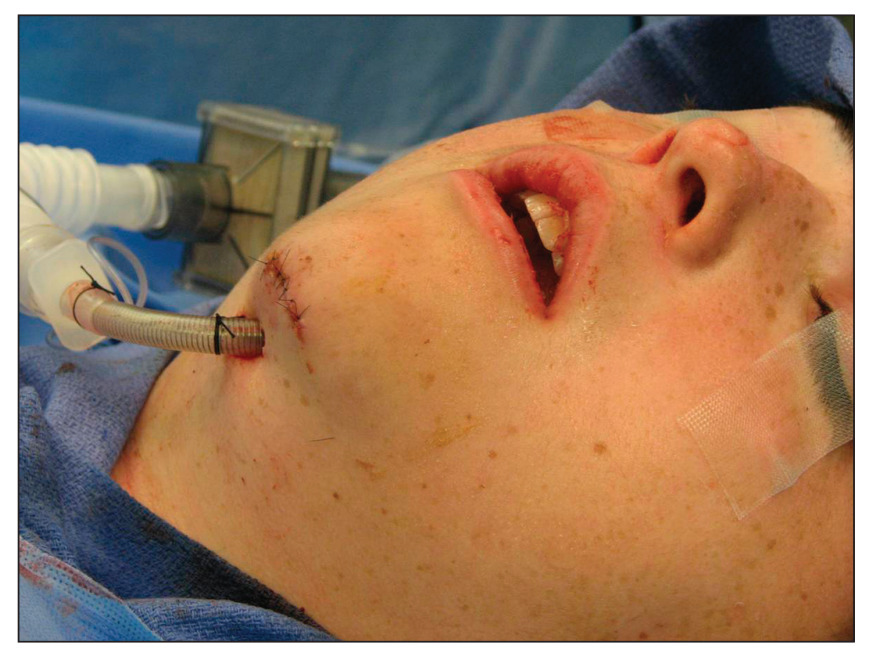

Figure 2) Submental intubation

fractures, also only had one complication - a superficial wound infection (8).

SI is not intended to replace tracheostomy, but in selected cases of facial trauma or orthognathic surgery it may be a better option. SI allows a safe and secure airway that will not interfere with surgical intervention of the midface and that may be done by the operating surgeon. This type of intubation is not intended for patients who will need long-term ventilation, but is an alternative for patients that need an airway only for operative intervention.

\section{REFERENCES}

1. Schade K, Borzotta A, Michaels A. Intracranial malposition of nasopharyngeal airway. J Trauma 2000;49:967-8.

2. Muzzi D, Losasso T-J, Cucchiara R-F. Complication from a nasopharyngeal airway in a patient with a basilar skull fracture. Anesthesiology 1991;74:366-8.

3. Altemir F-H. The submental route for endotracheal intubation. J Maxillofac Surg 1986;14:64-5.

4. Biglioli F, Pietro M, Goisis M, et al. Submental orotracheal intubation: An alternative to tracheostomy in transfacial cranial base surgery. Skull Base 2003;13:189-95.

5. Taglialatela S-C. Mucoceles as a complication of submandibular intubation. J Craniomaxillofac Surg 2004;32:335.

6. Davis C. Submental intubation in complex craniomaxillofacial trauma. ANZ J Surg 2004;74:379-81.

7. Schutz P, Hamed H. Submental intubation versus tracheostomy in maxillofacial trauma patients. J Oral Maxillofac Surg 2008;66:1404-9.

8. Caron G, Paquin R, Lessard MR, Trépanier CA, Landry PE.

Submental endotracheal intubation: An alternative to tracheotomy in patients with midfacial and panfacial fractures. J Trauma 2000;48:235-40. 